\title{
Elucidation of Genetic Diversity among Five Cultivars of Hibiscus Rosa-Sinensis Using Single Primer Amplification Reaction (Spar)
}

\author{
Reena Patel, Aditi Patel, Dharmesh Vaghasiya And Anju Nagee ${ }^{1}$ \\ ${ }^{I}$ (Department of Biotechnology, ARIBAS, Sardar patel university, India)
}

\begin{abstract}
Molecular marker assisted characterization is lacking in H.rosa sinensis. This study focuses on the genetic variability among five cultivars of H.rosa sinensis species by employing SPAR (RAPD, ISSR, SSR and DAMD) methods. In SPAR methods, Ten RAPD, Five ISSR, Three SSR and Seven DAMD primers were used to distinguish the genetic variability. Out of these Four primers showed 100\% polymorphism, while average polymorphism in RAPD and ISSR marker systems was $77 \%$ and $81.6 \%$ respectively and the cluster analysis showed a more or less similar pattern. Dendrograms revealed that the "YELLOW" and "ORANGE" cultivars are nearly located so they are not used in the hybridization process.
\end{abstract}

Keywords: Cultivars, H.rosa-sinensis, Markers, RAPD, SPAR

\section{Introduction}

Hibiscus rosa-sinensis (known as Chinese Hibiscus, Japa, Bunga Raya), the single form with the 5petaled blood-red blooms, is an ornamental shrub in the family Malvaceae native to East Asia[1].

\subsection{History/ background of Hibiscus}

H.rosa-sinensis is one of the most important medicinal plants extensively used by the traditional practitioners in India for its medicinal value. Flowers and leaves of H.rosa-sinensis are found to possess antioxidant, antifungal, anti-infectious, antimicrobial, anti-inflammatory, anti-diarrheic and antipyretic activity [2]. DNA-based diagnostics are now well established as a means to assay diversity at the locus, chromosome and whole genome levels [3].

\subsection{Single primer amplification reaction}

The SPAR (Single Primer Amplification Reaction) method offers a simple and economical means of genotype characterization. Many horticulturally important fruit crops including some guava varieties $[4,5]$, its few species [6,7] and its related species Feijoa sellowiana [7] have been characterized using RAPD markers. The ISSRs help to identify closely related cultivars and to study evolutionary processes and phylogenetic studies $[8,9]$. This marker system provides reproducible results that generate abundant polymorphism [10].

\subsection{Genetic diversity}

Assessment of genetic diversity in cultivated crops has important implications for breeding programs and for the conservation of genetic resources. Extensive use of closely-related cultivars by producers could result in vulnerability to pests and diseases. The importance of genetic diversity to crop vulnerability is widely recognized [11]. Despite the importance of $\mathrm{H}$. rosa-sinensis, little is known about its genetics. Its wide geographical distribution and varied habitats indicate that there is probably a large amount of genetic diversity [12].

\subsection{Molecular marker}

Among the molecular markers, Random amplified polymorphic DNA (RAPD) is increasingly being employed in genetic research owing to its speedy and convenient process [13]. ISSR and SSR uses microsatellites as primers in PCR reaction targeting multiple genomic loci to amplify mainly inter simple sequence repeats of different sizes. Heath et al., (1993) developed a novel technique called as DAMD, which uses PCR to direct the amplification to regions rich in minisatellites. In DAMD-PCR, a single primer from a minisatellite core is used to direct PCR from the regions rich in minisatellite.

\section{Result And Discussion}

In this study, total 25 primers were used to check the genetic variation in 5 different cultivars of H.rosa sinensis. All the primers gave satisfactory and reproducible bands. The banding pattern of the RAPD, DAMD analysis for two primers has been shown in fig 1 and fig 2 respectively.

Average polymorphism for RAPD analysis was found to be $84.75 \%$ whereas for ISSR analysis it was 88.03\% and for SSR and DAMD it is very low. Detailed combined analysis is given in the table 1. The cophenetic correlation value was studied for all these markers is $\quad r=0.9365$ and found that all the markers are good fit for cluster analysis. Dendogram for the combined primer analysis is given in the fig- 7 . 

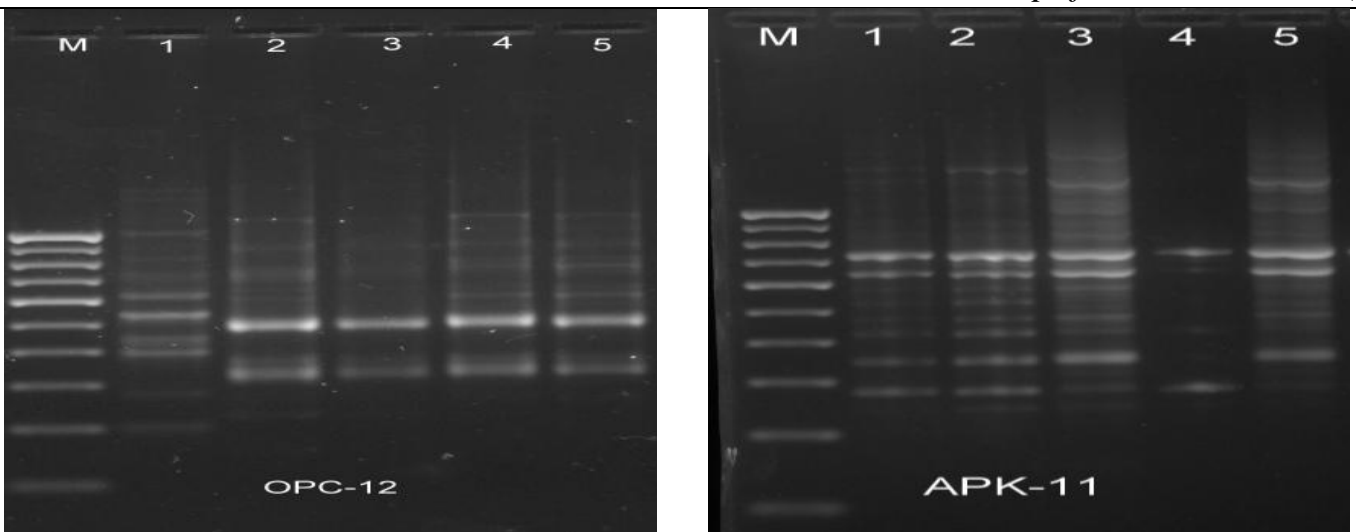

Figure 1 - RAPD Banding Pattern In All Five Cultivars. (M1= 100 Bp. Marker And 1-5 Are Different Cultivars (RED, PINK, WHITE,ORANGE,YELLOW)
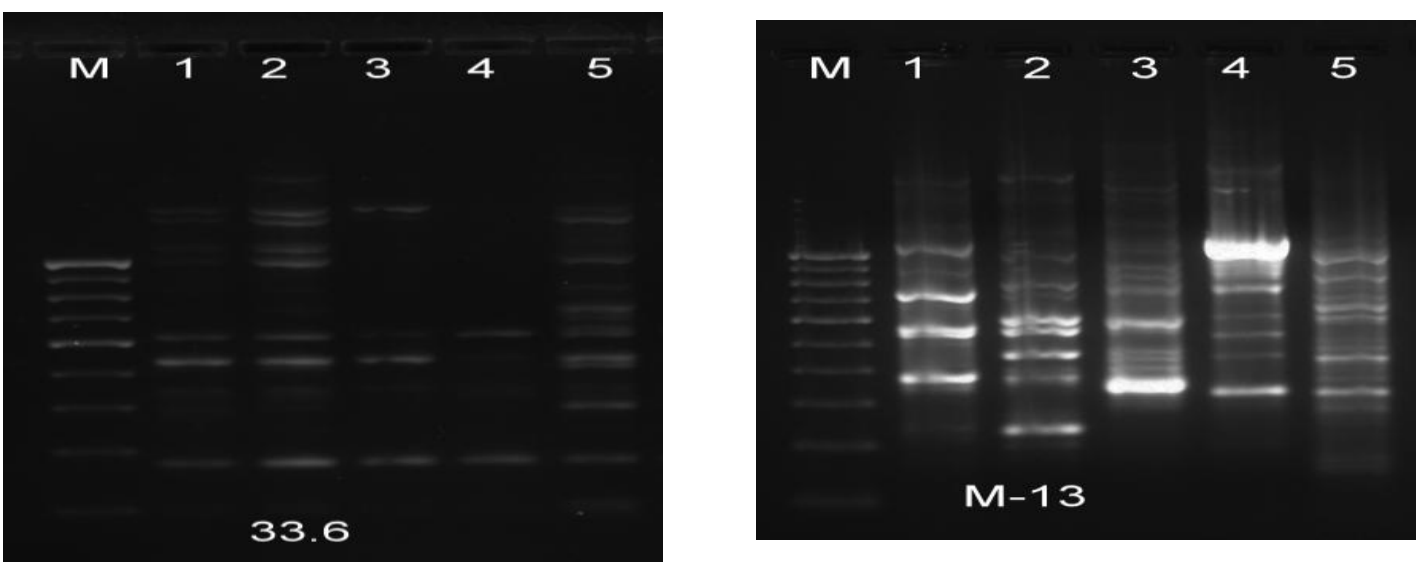

Figure 2 - DAMD Banding Pattern In All Five Cultivars. (M1= 100 Bp. Marker And 1-5 Are Different Cultivars(RED, PINK, WHITE,ORANGE,YELLOW)

Table: 1 Detail Combined Table

\begin{tabular}{|c|c|c|c|c|}
\hline Marker & RAPD & SSR & ISSR & DAMD \\
\hline Primers Used & 10 & 2 & 3 & 5 \\
\hline Total amplicons obtained & 499 & 31 & 98 & 159 \\
\hline Total loci analysed & 204 & 14 & 44 & 62 \\
\hline Total No of polymorphic band & 419 & 11 & 88 & 124 \\
\hline Total No of monomorphic band & 80 & 20 & 10 & 35 \\
\hline Polymorphism \% & 84.75 & 34.87 & 88.03 & 76.84 \\
\hline Average No of bands/primer & 49.9 & 15.5 & 32.6 & 31.8 \\
\hline Average No of polymorphic bands/primer & 41.9 & 5.5 & 29.3 & 24.8 \\
\hline Range of band molecular weight & $267-2469$ & $70-359$ & $268-1537$ & $201-1294$ \\
\hline Average polymorphism Information Content (PIC value) & 0.935 & 0.759 & 0.916 & 0.887 \\
\hline
\end{tabular}

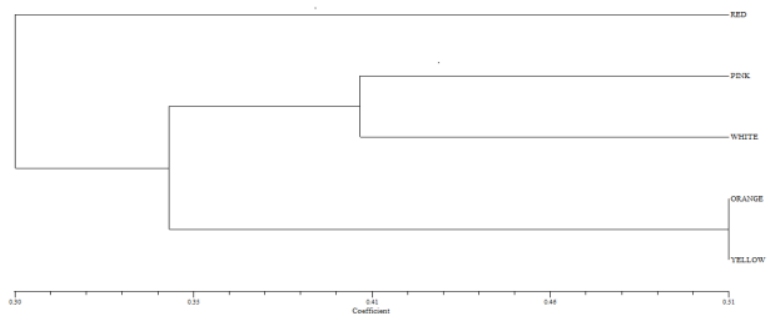

Figure 3 Dendrogram showing the relationships among the five cultivars of Hibiscus rosa-sinensis based on jaccard's similarity coefficient revealed by RAPD primer 


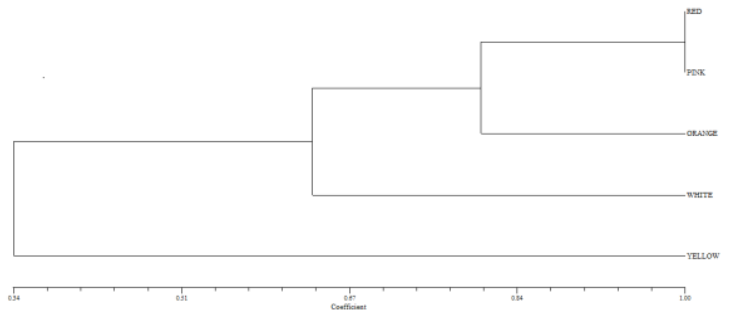

Figure 4 Dendrogram showing the relationships among the five cultivars of Hibiscus rosa-sinensis based on jaccard's similarity coefficient revealed by SSR primers.

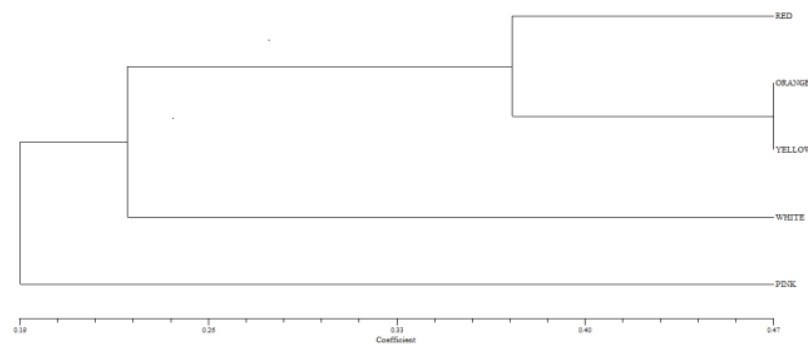

Figure 5 Dendrogram showing the relationships among the five cultivars of Hibiscus rosa-sinensis based on jaccard's similarity coefficient revealed by ISSR primers.

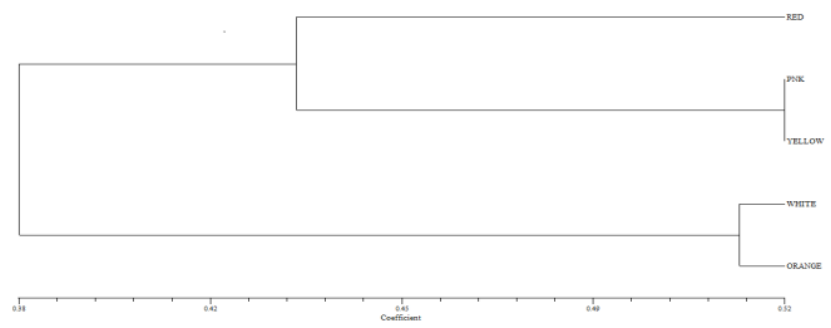

Figure 6 Dendrogram showing the relationships among the five cultivars of Hibiscus rosa-sinensis based on jaccard's similarity coefficient revealed by DAMD primers.

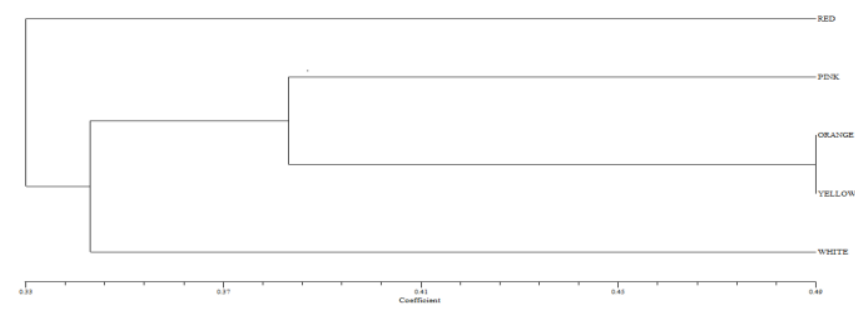

Figure 7 Dendrogram showing the relationships among the five cultivars of Hibiscus rosa-sinensis based on jaccard's similarity coefficient revealed by combination of RAPD,SSR,ISSR, DAMD primers.

Dendogram revealed that cultivar 'ORANGE' and 'YELLOW' had equal similarities. Thus, these two cultivars could not be used in hybridization process. This study could identify diverse genotypes like 'RED' and 'PINK' cultivars for their use in hybridization program of Hibiscus rosa-sinensis. Molecular markers are useful in the assessment of $\mathrm{H}$. rosa-sinensis diversity, through detection of duplicate samples in germplasm collection, and the selection of a core collection to enhance the efficacy of germplasm management for use in $\mathrm{H}$. rosasinensis breeding and conservation programs. The genetic diversity obtained in this study might be useful in future strategies for evolution of desired genotypes. Our results are in agreement with previous studies reporting a clear separation between the cultivated varities of Hibiscus rosa-sinensis observed by Ibtisam hammad, 2009.

Our investigation demonstrates the power of RAPD, ISSR, SSR and DAMD fingerprinting to study genetic diversity in closely related taxa. They studied that RAPD and ISSR fingerprints as useful genetic markers for analysis of genetic diversity, varietal identification, and phylogenetic relationships in peanut (Arachis hypogaea) cultivars and wild species. 


\subsection{Plant material}

\section{Exprimental Section}

Five cultivars with different flower colors (RED, PINK, WHITE, ORANGE and YELLOW) of Hibiscus rosa-sinensis were collected from nearby area of Anand city, Gujarat, India. Fresh and young leaf samples were collected to isolate genomic DNA.

\subsection{Genomic DNA Isolation}

Young leaf tissue $(200 \mathrm{mg}$ ) was used for the extraction of genomic DNA with the help of protocol of Doyle and Doyle [14] with some modifications. Leaves were ground in liquid nitrogen to make a fine powder using pre-chilled mortar and pestle. The fine powder was used for DNA extraction. $800 \mu$ l of CTAB buffer (2M $\mathrm{NaCl}, 100 \mathrm{mM}$ Tris $\mathrm{HCl}, 20 \mathrm{mM}$ EDTA (pH8), 3\% CTAB, 1.5\% PVP (w/v), 0.2\% 2-mercaptoethanol (v/v) added immediately before use) was added to each eppendorf tube containing the crushed leaf material and vortexed to mix. The mixture was incubated for 60 minutes at $65^{\circ} \mathrm{C}$. Equal volume of chloroform: isoamyl alcohol (24:1) was added. Tubes were then kept on shaking until a homogenous mixture was obtained. Samples were then centrifuged at $10,000 \mathrm{rpm}$ for 10 minutes. The supernatant was carefully decanted and transferred to a new tube. The above steps, beginning with the addition of chloroform: isoamylalcohol (24:1) and ending with decanting of supernatant, were repeated twice. The supernatant was precipitated by adding $1 / 10^{\text {th }}$ volume of $3 \mathrm{M}$ sodium acetate and double volume of cold isopropanol. The tubes were incubated at $-20^{\circ} \mathrm{C}$ overnight for complete precipitation. Samples were centrifuged at $10,000 \mathrm{rpm}$ for 10 minutes to pellet the DNA. The supernatant was then discarded which was followed by two times washing of pellet with $70 \%$ ethanol. Pellet was dried at room temperature and re-suspended in TE buffer (10 mM Tris HCl, $1 \mathrm{mM}$ EDTA, pH 8.0). RNase A $(20 \mathrm{mg} / \mathrm{ml})$ was added and incubated at $37^{\circ} \mathrm{C}$ for one hour. To this $1 / 10^{\text {th }}$ volume of $3 \mathrm{M}$ Sodium acetate and double volume of cold isopropanol was added and incubated at $-20^{\circ} \mathrm{C}$ for one hour to re-precipitate DNA. The solution was centrifuged at $10,000 \mathrm{rpm}$ for 10 minutes. DNA pellet was dried at room temperature and resuspended in TE buffer. The quantity and quality of DNA extracted were estimated using NANODROP ${ }^{\mathrm{TM}}$ 1000 spectrophotomer and Agarose gel (0.8\%) electrophoresis.

Table:2 List of primers with their nucleotide sequence used in the amplification reaction

\begin{tabular}{|l|l|l|l|}
\hline $\begin{array}{l}\text { RAPD } \\
\text { primer }\end{array}$ & Sequence & ISSR primer & Sequence \\
\hline OPD-2 & GGACCCAACC & IG-14 & GAGAGAGAGAGAGAGAA \\
\hline OPD-8 & GTGTGCCCCA & IG-10 & AGAGAGAGAGAGAGAGT \\
\hline OPD-16 & AGGGCGTAAG & HB-09 & GTGTGTGTGTGTGG \\
\hline OPD-20 & AACCCGGTCA & HB-15 & GTCGTCGTCGC \\
\hline OPF-1 & ACGGATCCTG & 98B & CACACATATATAGT \\
\hline OPF-8 & GGGATATCCC & $\begin{array}{l}\text { DAMD } \\
\text { primer }\end{array}$ & \\
\hline OPC-12 & TGTCATCCCC & URP1F & ATCCAAGGTCCGAGACAACC \\
\hline OPS-01 & CTACTGCGCT & URP2F & GTGTGCGATCAGTTGCTGGG \\
\hline OPA-01 & TGCCGAGCTG & URP9F & ATGTGTGCGATCAGTTGCTG \\
\hline APK-11 & GACCGACACT & FV11EX8 & ATGCACACACACAGG \\
\hline $\begin{array}{l}\text { SSR } \\
\text { primer }\end{array}$ & & FV11EX8C & CCTGTGTGTGTGCAT \\
\hline (GAA)7 & GAAGAAGAAGAAGAAGAAGAA & 33.6 & GGAGGTGGGCA \\
\hline (AT)7 & ATATATATATATAT & M13 & GAGGGTGGCGGCTCT \\
\hline (AAGC)3 & AAGCAAGCAAGC & & \\
\hline
\end{tabular}

\subsection{RAPD Reaction}

The PCR reactions were performed in 25 $\mu$ l mixture containing 20-40 ng of genomic DNA, $0.2 \mathrm{U}$ Taq DNA polymerase, $2.5 \mathrm{mM}$ of each dNTPs (dATP, dTTP, dCTP and dGTP), 10X assay buffer (10 mM Tris-Cl; pH 9.0, $1.5 \mathrm{mM} \mathrm{MgCl} 2,50 \mathrm{mM} \mathrm{KCl}$ and $0.01 \%$ gelatin) [15]. Ten RAPD decamer primers $(1.5 \mu \mathrm{M})$ with $60-$ $70 \%$ GC contents were used to amplify the DNA using thermal cycler. The standardized PCR reaction conditions were as follows : initial denaturation step at $94^{\circ} \mathrm{C}$ for 4 minutes followed by 45 cycles of $94^{\circ} \mathrm{C}$ for 1 minute, $35-37^{\circ} \mathrm{C}$ (depending on synthesized primer) for 1 minute and $72^{\circ} \mathrm{C}$ for 2 minutes with a final extension at $72^{\circ} \mathrm{C}$ for 5 minutes. The holding temperature was $4^{\circ} \mathrm{C}$.

\subsection{ISSR and SSR Reaction}

For ISSR stud the initial optimization of PCR was conducted including concentration of template DNA primer, $\mathrm{MgCl} 2$, number of PCR cycle and annealing temperature. The PCR reaction had a total volume of $25 \mathrm{ml}$ containing $20 \mathrm{ng}$ templates DNA, $100 \mathrm{mM}$ each dNTPs, $20 \mathrm{ng}$ of oligonucleotides synthesized primer, $2.5 \mathrm{mM} \mathrm{MgCl} 2,1 \_$Taq buffer (10mM Tris-HCl [pH 9.0], $50 \mathrm{mM} \mathrm{KCl}$, and $0.01 \%$ gelatin) and $0.5 \mathrm{U}$ Taq DNA polymerase. DNA amplification was performed. The programmed for a preliminary $5 \mathrm{~min}$ denaturation step at $94^{\circ} \mathrm{C}$, followed by 40 cycles of denaturation at $94^{\circ} \mathrm{C}$ for $20 \mathrm{~s}$., annealing temperature depending on the synthesize primer (ranged from $32-56^{\circ} \mathrm{C}$ ) for $30 \mathrm{~s}$. and extension at $72^{\circ} \mathrm{C}$ for $45 \mathrm{~s}$., finally at $72^{\circ} \mathrm{C}$ for $5 \mathrm{~min}$

\subsection{DAMD Reaction}

The reaction mixtures contained $50 \mathrm{ng}$ of template DNA, 10 pmoles primer, $3.0 \mathrm{mM}$ magnesium ions, $200 \mathrm{mM}$ each dNTP, 0.5 Units enzyme and $1 \mathrm{X}$ buffer. The volume was made upto $25 \mathrm{ml}$ with deionized sterile 
water. The optimum annealing temperatures depending on the synthesize primer. The cycling parameters were as follows: First cycle of $94^{\circ} \mathrm{C}$ for 1 minute for initial denaturation then 35 cycles of incubation at $94^{\circ} \mathrm{C}$ for 30 seconds, at annealing temperature for 1 minute and $72^{\circ} \mathrm{C}$ for 1 minute [16]. Last cycle allowed 5 minute at $72^{\circ} \mathrm{C}$ for extension. These conditions were used with all minisatellite primers

\subsection{DNA electrophoresis}

Amplified fragments were separated electrophoretically on $1.5 \%$ (w/v) agarose (Low EEO, HIMEDIA) gel with $1 \mathrm{X}$ TBE (Tris- Borate -EDTA) buffer and stained with ethidium bromide (EtBr). The 100 bp DNA ladder plus molecular weight marker was used to compare the molecular weight of amplified products. The gel was then visualized under UV light and photographs were analyzed by using gel - documentation system.

\subsection{Data Analysis}

The RAPD bands were scored as discrete variables, using 1 to indicate the presence and 0 for absence of a band to create a binary data matrix. The data obtained were subjected to the construction of similarity matrix using Dice coefficient by SIMQUAL function. The similarity values were used for cluster analysis. Sequential Agglomerative Hierarchical Nesting (SAHN) clustering was conducted using Unweighted Pair Group Method of Arithmetic Means (UPGMA) method. Data analysis was carried out using NTSYSpc (Numerical taxonomy system, applied biostatistics, Inc., New York, USA, software version 2.02e) (Rohlf, 1998).

\section{Conclusion}

In the present study, RAPD and ISSR markers revealed high degree of polymorphism $84.75 \%$ and $88.03 \%$ respectively among these cultivars. The molecular-markers based UPGMA cluster analysis demonstrated that all the cultivated genotypes were well separated from each other. From the experimental observations, it can be concluded that SPAR analysis can detect sufficient polymorphism to differentiate the cultivars of $H$. rosa-sinensis. Thus it is highly recommendable for studying their genetic relationships.

This markers proved as useful means in the assessment of Hibiscus rosa-sinensis diversity through detection of duplicate samples in germplasm collection. The cluster pattern may be used to design a strategy to maintain or enhance the genetic diversity of future varieties for use in H. rosa-sinensis breeding and conservation programs. The genetic diversity obtained in this study might be helpful in future strategies for evolution of desired genotypes and further development of new H. rosa-sinensis cultivars.

\section{References}

[1] Fryxell, P.A. and S.H. Hashmi. 1971. The segregation of Raydero from Hibiscus, Bot. Gaz., 132: 57-62

[2] David Bruce Leonard, L.Ac. (1998) Healing plants of the Hawaiian kingdom-Hibiscus rosa-sinensis (Aloalo), Roast Duck Production.

[3] Tingey and Tufo (1993) Genetic analysis with Random Amplified Polymorphic DNA markers. Plant physiol, 101: $349-352$.

[4] Prakash, D. H., Narayanaswamy, P., Sondur, S. N. (2002). Analysis of molecular diversity in guava using RAPD markers. The Journal of Horticultural Science and Biotechnology, 77(3): 287-293.

[5] Dahiya, K. K., Sunil, A., Karihaloo, J. K. (2002). DNA fingerprinting of guava (Psidium guajava L.) cultivars using RAPD markers. Indian Journal of Plant Genetic Resource 15(2):112-115.

[6] Sharma, A. S. Sehrawat, S. K., Singhrot, R. S., Boora, K. S. (2007). Assessment of genetic diversity and diversity relationship among Psidium spp. through RAPD analysis. Acta Horticulturae 735: 71-77.

[7] Dettori, M. T., Palombi, M. A. (2000). Identification of Feijoa sellowiana Berg. accessions by RAPD markers. Scientia Horticulturae. 86: 279-290.

[8] Prevost, A., Wilkinson M. J. (1999). A new system of comparing PCR primers applied to ISSR fingerprinting of potato cultivars. Theoretical and Appied Genetics, 98: 107-112.

[9] Raina, S. N., Rani, V., Kojima, T., Ogihara, Y., Singh, K. P., Devarumath, R. M. (2001). RAPD and ISSR fingerprints as useful genetic markers for analysis of genetic diversity, varietal identification, and phylogenetic relationship in peanut (Arachis hypogaea) cultivars and wild species. Genome 44: 763-772.

[10] Tsumura, Y., Ohba, K., Strauss, S. H. (1996). Diversity and inheritance of Inter-Simple Sequence Repeat polymorphisms in Douglasfir (Pseudotsuga menziesii) and Sugi (Cryptomeria japonica). Theoretical and Applied Genetics 92: 40-45.

[11] Van-Esbroeck, G. and Bowman, D.T. (1998) Cotton germplasm diversity and its importance to cultivar development. J. Cotton Sci., 2: 121-129.

[12] Ibtisam hammad (2009). Genetic variation among Hibiscus Rosa-sinensis (Malvaceae) of different flower colors using ISSR and Isozymes. Australian Journal of Basic and Applied Sciences, 3(1): 113-125.

[13] Williams, J.G.K., Hanafey, M.K., Rafalski J.A. and Tingey, S.V. (1993) Genetic analysis using random amplified polymorphic DNA markers. Methods Enzymol 218: 704-740.

[14] Doyle, J.J. and Doyle, J.L. (1987) A rapid DNA isolation procedure for small quantities of fresh leaf tissue. Phytochem. Bull., 19: 1115 .

[15] Williams, J.G.K., Kubelik, A.R., Livak, K.J., Rafalski, J.A. and Tingey, S.V. (1990) DNA polymorphisms amplified by arbitrary primers are useful as genetic markers. Nucl Acids Res, 18: 6531-6535.

[16] Zhou Z, Bebeli PJ, Somers DJ, Gustafson JP (1997) Direct amplification of minisatellite-region DNA with VNTR core sequences in the genus Oryza. Theor Appl Genet 95:42-949 